\title{
A Prospective Multicenter Trial of the TransForm Occlusion Balloon Catheter: Trial Design and Results
}

\author{
M. Asif Taqia Syed A. Quadria Ajit S. Puri ${ }^{b}$ Brian F. Fitzsimmons ${ }^{c}$ \\ Jianhua Nancy Jin ${ }^{i}$ Ansaar T. Rai ${ }^{d}$ Curtis A. Given $2{ }^{\text {e }}{ }^{\text {Javier Masso }}{ }^{f}$ \\ Ciaran J. Powers ${ }^{g}$ Joey D. English ${ }^{\mathrm{h}}$ Osama O. Zaidat ${ }^{j}$ \\ ${ }^{a}$ California Institute of Neuroscience and Los Robles Hospital and Medical Center, Thousand \\ Oaks, CA, b Department of Radiology, University of Massachusetts Medical School and UMass \\ Memorial Medical Center, Worcester, MA, ' Departments of Neurology, Neurosurgery and \\ Radiology, Medical College of Wisconsin and Froedtert Hospital, Milwaukee, WI, d Department \\ of Interventional Neuroradiology, West Virginia University Hospital, Morgantown, WV,

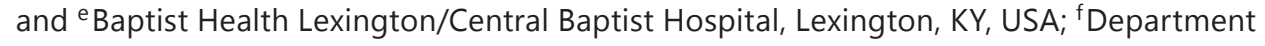 \\ of Neuroradiology, Hospital Universitario Donostia, San Sebastian, Spain; 9 Department \\ of Neurological Surgery, The Ohio State University Wexner Medical Center, Columbus, \\ $\mathrm{OH},{ }^{h}$ Neurointerventional Surgery, California Pacific Medical Center, San Francisco, CA, \\ iDepartment of Biostatistics, Stryker Neurovascular, Fremont, CA, and jDepartments of \\ Endovascular Neurosurgery and Stroke, St. Vincent Mercy Medical Center, Toledo, OH, USA
}

\section{Keywords}

Balloon-assisted coil embolization · Balloon-assisted coiling · TransForm Occlusion Balloon Catheter · Single-lumen balloon · Intracranial aneurysms $\cdot$ Trial

\begin{abstract}
Background and Purpose: Adjunctive treatments like balloon-assisted coil embolization (BACE) and stent-assisted coil embolization play a major role in the treatment of wide-neck and large intracranial aneurysms. The TransForm ${ }^{\text {TM }}$ Occlusion Balloon Catheter (TOBC) registry is intended to evaluate the safety, efficacy, and efficiency of BACE using the TOBC. Method and Study Design: The TOBC registry is a prospective multicenter registry trial. Seven sites in the USA and 1 site in Spain participated and enrolled 81 patients. Results: The performance and safety of the TOBC was evaluated based on scoring for different variables. Scores were
\end{abstract}

The abstract was presented at the 13th Congress of the World Federation of Interventional and Therapeutic Neuroradiology in Gold Coast, QLD, Australia, from November 9-13, 2015. 
measured using a semiquantitative rating scale $(1=$ excellent, $5=$ poor $)$. The mean scores for these variables were as follows: visibility under fluoroscopy, 1.8; ability to reach the intended site, 1.6; stability during first positioning, 1.5; stability during inflation, 1.6; stability during deflation, 1.6; ability to temporarily stop flow, 1.6; and ability to assist in coil embolization, 1.7. The mean inflation and deflation times were 4.9 and $5.6 \mathrm{~s}$, respectively. Complete obliteration of the aneurysm (Raymond class I) was achieved in $69.4 \%$ of the BACE cases. Thrombus formation occurred in 4/81 (4.8\%) of the cases. In all cases, the thrombus resolved with medications, no patient suffered an infarction, and an underlying hypercoagulable state from subarachnoid hemorrhage was considered a contributing factor. Vessel rupture occurred in $1 / 81$ $(1.2 \%)$ of the cases, but was unrelated to TOBC use. Conclusion: BACE using the TOBC is safe and effective. All variables assessed for performance showed good-to-excellent results.

(c) 2017 S. Karger AG, Basel

\section{Introduction}

In the past decade, there has been a rapid decline in clipping and a steep incline in endovascular treatment of aneurysms [1]. Although more aneurysms are now being treated with the endovascular technique, treatment of wide-neck and bifurcation aneurysms with the endovascular technique remains a challenge [2]. The difficulties include herniation of coils in the parent vessel, inability to differentiate the neck and parent vessel interface, and protection of vessel branches at the neck.

The treatment options for wide-neck aneurysms include stent-assisted coil embolization (SACE), balloon-assisted coil embolization (BACE), or treatment with flow diverters (FDs). Both SACE and FD require the use of dual antiplatelet therapy and create a theoretical longterm risk of stroke from platelet aggregation on the implant. The required use of dual antiplatelet agents limits the use of SACE or FDs in ruptured aneurysms. On the other hand, BACE does not require the use of antiplatelet agents. In 1997, Moret et al. [3] initially reported on the use of BACE, when a balloon catheter was placed across the neck of an aneurysm while Guglielmi detachable coils were deployed. Since then, several case series and case reports have been published showing the success of BACE when used with continually evolving balloon catheters [2, 4-21].

Older balloon catheters like the Endeavor (Target Therapeutics, Fremont, CA, USA) and the Grapevine or Cirrus/Solstice (Medtronic-MIS Corp., Sunnyvale, CA, USA) have been taken off the market. Commonly used compliant balloon catheters include the HyperForm ${ }^{\mathrm{TM}}$ and HyperGlide ${ }^{\mathrm{TM}}$ balloons (Covidien/ev3, Irvine, CA, USA), the Scepter balloon (Scepter $\mathrm{C}^{\mathrm{TM}}$ or Scepter XC ${ }^{\mathrm{TM}}$; MicroVention, Inc., Tustin, CA, USA), the Ascent ${ }^{\mathrm{TM}}$ balloon (Codman Neuro, Raynham, MA, USA), and the TransForm ${ }^{\mathrm{TM}}$ balloon (Stryker Neurovascular, Fremont, CA, USA).

The Scepter is a coaxial dual-lumen compliant balloon that allows for the possibility of coil embolization through the balloon catheter utilizing a 0.014 -inch wire $[16,19]$. The HyperForm and HyperGlide balloon catheters are single-lumen compliant balloons utilizing 0.010 -inch wires $[2,12]$. The Ascent is also a coaxial dual-lumen compliant balloon catheter which can be used with a 0.014-inch wire [22]. The use of 0.010-inch wires allowed the HyperForm and HyperGlide balloons to be a smaller system, but they can be hard to navigate due to limited navigability of the 0.010-inch wire. On the other hand, the Ascent and Scepter balloons on a 0.014-inch wire have the advantage of being dual lumen, but their relatively large outer diameters can make it difficult to navigate them into distal intracranial branches.

The TransForm Occlusion Balloon Catheter (TOBC) is indicated for use in the neurovasculature to temporarily stop or control blood flow, as well as for BACE of intracranial aneu- 
Taqi et al.: A Prospective Multicenter Trial of the TransForm Occlusion Balloon Catheter: Trial Design and Results

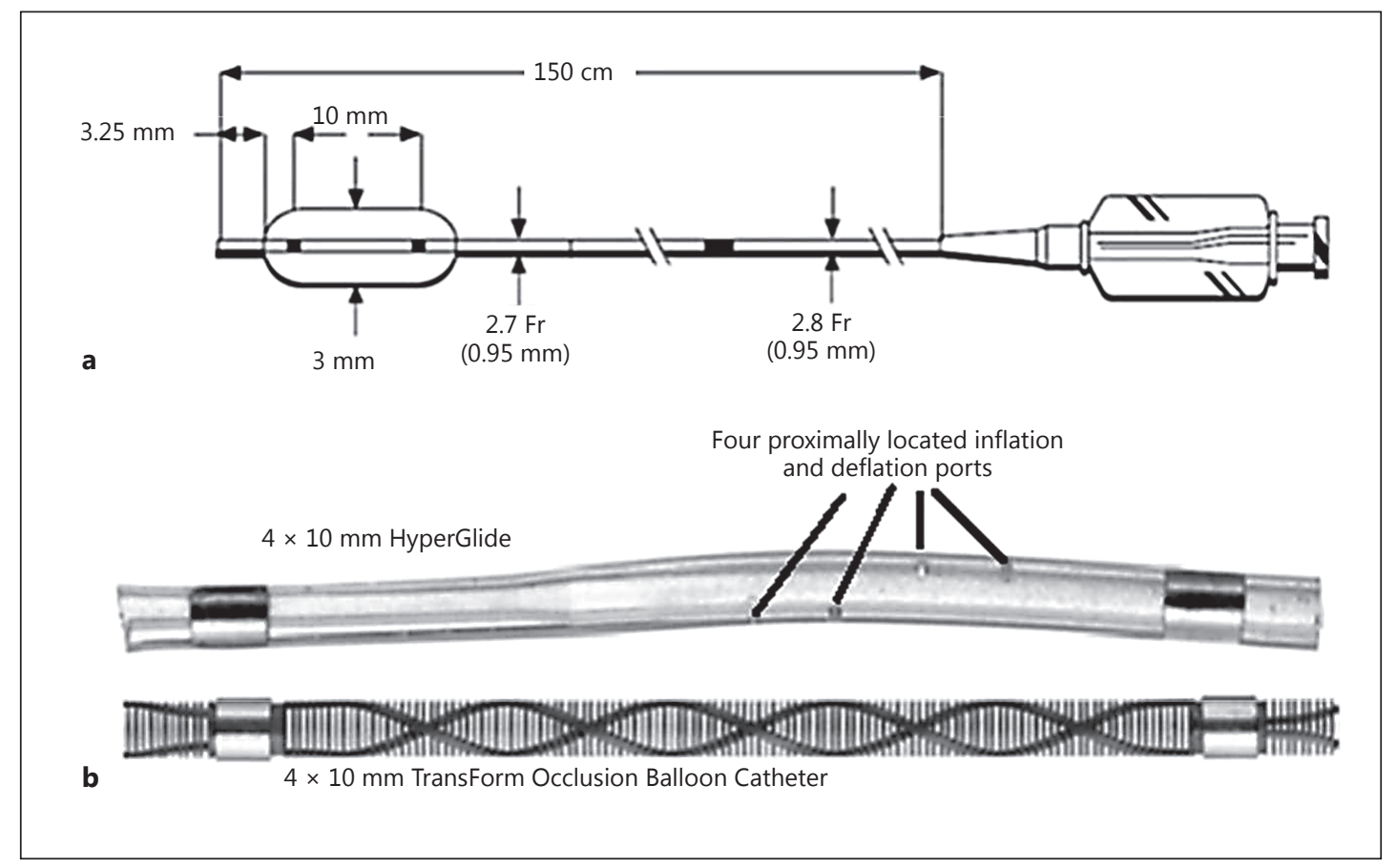

Fig. 1. a TransForm ${ }^{\mathrm{TM}}$ Occlusion Balloon Catheter with a catheter length of $150 \mathrm{~cm}$, proximal outer diameter of $2.8 \mathrm{Fr}$, distal outer diameter of $2.7 \mathrm{Fr}$, distal tip of $3.25 \mathrm{~mm}$, and fluoro-saver marker $94 \mathrm{~cm}$ from the distal tip. b $4 \times 10 \mathrm{~mm}$ HyperGlide with four proximally located inflation and deflation ports as compared to a $4 \times$ $10 \mathrm{~mm}$ TransForm Occlusion Balloon Catheter with micromachined slits for inflation and deflation (designed to allow for faster deflation, the use of higher contrast levels, increased visibility, and reduced procedure times).

rysms. The primary objective of this TOBC registry was to evaluate real-world data on the safety and performance of the TOBC when used in neurointerventional procedures. To our knowledge, this is the first prospective multicenter registry for BACE of intracranial aneurysms.

\section{Device Description}

The TOBC is a single-lumen, over-the-wire, compliant, and super-compliant balloon catheter having variable-stiffness reinforced catheters. The balloon is designed to provide an inflatable segment of a known diameter and length at recommended inflation volumes. The TOBC is compatible with guidewires of 0.014-inch outer diameter and 5-Fr or larger guide catheters, and has an effective length of $150 \mathrm{~cm}$ (Fig. 1a).

The outer surface of the catheter's distal segment is coated with a lubricant hydrophilic coating designed to reduce friction. To facilitate fluoroscopic visualization, each catheter has two radiopaque markers at the distal and proximal ends of the balloon which are used to position the balloon at the intended treatment site. The proximal end of the balloon catheter incorporates a strain relief and a standard Luer fitting to facilitate the attachment of accessories. The delivery wire has four different material transition zones. The TOBC incorporates hundreds of micromachined slits for contrast infusion, allowing for controlled inflation and balloon stability (Fig. 1b). In the USA, the on-label indications for use of the TOBC are for BACE, and to temporarily stop or control blood flow in the neurovasculature, while in Europe the on-label indication for use also includes the treatment of vasospasm. 
Taqi et al.: A Prospective Multicenter Trial of the TransForm Occlusion Balloon Catheter: Trial Design and Results

\section{Methods}

Study Design

This study was a prospective, single-arm, nonrandomized, multicenter, observational registry. Patients undergoing a neurointerventional procedure that included the use of an occlusion balloon catheter and whose anatomy allowed for safe delivery of the TOBC were enrolled. Each study site obtained approval of their respective Institutional Review Board before enrollment. All enrolled subjects consented to participation in the registry and the publication of acquired data afterwards.

Observational assessments of balloon performance were recorded by each treating physician (site principal investigator [PI]) for each case. This occurred immediately after the procedure and was done using a semiquantitative grading scale. Variables that were assessed included the ability of the TOBC to reach the target site, the ability of the TOBC to temporarily stop or control blood flow, the ability of the TOBC to assist in coil embolization of intracranial aneurysms, visibility of the TOBC on angiography, the amount of time required for the TOBC to inflate/deflate, and the stability of the TOBC during positioning and inflation/ deflation of the balloon. A 5-point rating system was used to evaluate balloon performance, with each of the 5 ratings ("excellent," "very good," "good," "fair," and "poor") being assigned a corresponding numerical value $(1,2,3,4$, and 5$)$ that was used to represent the TOBC's performance utility in relation to the various parameters being assessed. For a given parameter, the lower the overall number the better.

For a given subject, participation in the registry was completed upon removal of the guide catheter after the procedure. Since this was an observational registry for assessment of intraprocedural balloon performance, there was no postprocedural radiological imaging and no postprocedural follow-up visits were required. Postprocedural neurological outcomes were assessed and reported by the PIs who participated in the study.

\section{Data Collection}

Patients' age, sex, aneurysm size and location, rupture status at presentation, clinical symptoms at presentation, degree of aneurysm occlusion, type of balloon catheters and microguidewires used, amount of contrast used, inflation and deflation times, and technical and clinical complications were captured. Angiographic results were classified as described by Raymond et al. [23, 24]. All adverse events (AEs) that occurred from the time of guide catheter insertion until removal of the guide catheter were collected.

The data were collected via an Internet-accessible, secure electronic data capture system using electronic case report forms. Remote data monitoring via the electronic data capture system was utilized for this registry.

\section{AE Definitions and Classification}

$\mathrm{An} \mathrm{AE}$ for this registry was defined as any untoward medical occurrence in a subject which was not related to the device under investigation. A severe AE (SAE) was defined as an AE that led to death, resulted in a life-threatening illness/injury or permanent impairment of a body structure or a body function, or required prolongation of existing hospitalization, or any medical/surgical intervention or any event that led to fetal distress, fetal death, or a congenital abnormality or birth defect in pregnant subjects.

Any untoward and unintended response to the medical device resulting from insufficiencies or inadequacies in the instructions for use, with the deployment of the device, or as a result of a user error was classified as an adverse device effect (ADE). An ADE that resulted in any of the consequences characteristic of an SAE was defined as a serious ADE. The seriousness of any AEs was assessed by the site PIs and was reported to the sponsor's project manager, the sponsor's safety manager, and the study PI. All AEs were remotely monitored, and the site PIs were responsible for assessing and reporting whether any AE occurred in relation to the study device or the index procedure. There was no independent adjudication committee for the reported events.

\section{Statistical Analysis}

Statistical analyses were performed using SAS System software version 9.4 (2000, SAS Institute, Inc., Cary, NC, USA). Descriptive statistics were used to summarize each of the various clinical and performance parameters being assessed (i.e., visibility, stability during inflation, etc.). No comparisons were performed. Data are presented as the mean and range for continuous variables and as a frequency for categorical variables. The denominator is the intent-to-treat population. 
Table 1. Subject demographics $(n=81)$

\begin{tabular}{lc}
\hline Age (range), years & $54.78(21-84)$ \\
Female & $69.1 \%(56)$ \\
Comorbidities & $80.2 \%(65)$ \\
Hypertension & $55.6 \%(45)$ \\
Coronary artery disease & $13.6 \%(11)$ \\
Intracranial/extracranial atherosclerosis & $2.5 \%(2)$ \\
Smoking & $45.7 \%(37)$ \\
Current illicit drug use & $4.9 \%(4)$ \\
Vasculitis/moyamoya disease & $1.2 \%(1)$ \\
History of stroke/transient ischemic attack & $14.8 \%(12)$ \\
History of intracranial hemorrhage & $9.9 \%(8)$ \\
Diabetes mellitus & $8.6 \%(7)$ \\
Hyperlipidemia/hypercholesterolemia & $29.6 \%(24)$ \\
Arteriovenous malformation & $2.5 \%(2)$ \\
Multiple intracranial aneurysms & $16.0 \%(13)$ \\
\hline
\end{tabular}

Table 2. Aneurysm characteristics $(n=72)$

Anterior circulation aneurysms

Mean aneurysm diameter \pm SD, $\mathrm{mm}$

Aneurysm neck width $\geq 4 \mathrm{~mm}$

Dome-to-neck ratio ${ }^{1}<2$

Ruptured aneurysms
$82 \%$

$6.8 \pm 3.6$

$46 \%$

$83 \%$

$50 \%$

${ }^{1}$ Calculated based on the short-axis measurement in aneurysms that were cylindrical in shape.

\section{Results}

Eighty-one patients were enrolled at 8 study sites between December 2013 and January 2015; 69.14\% were female, and the mean age was 55 years (see Table 1 for demographics). Aneurysm characteristics were reported for 72 treatment locations (Table 2). Sixteen percent of the patients had more than 1 aneurysm treated; $82 \%$ (59/72) of the aneurysms were located in the anterior circulation, and 50\% were ruptured. Fifty percent (36/72) of the lesions reported were bifurcation aneurysms; the location of these aneurysms was only reported for 38.9\% (14/36) of these lesions, with 8/14 being M1 middle cerebral artery bifurcation lesions, and $6 / 14$ being bifurcation lesions in the basilar artery.

The mean vessel diameter proximal to the target treated was noted for 91/92 treatment sites. The mean diameter treated was $3.29 \mathrm{~mm}$ (SD \pm 1.19 ), with the minimum being $1 \mathrm{~mm}$ and the maximum $7.4 \mathrm{~mm}$.

The mean vessel diameter distal to the target treated was noted for 58/92 treatment sites. The mean diameter treated was $2.9 \mathrm{~mm}(\mathrm{SD} \pm 1.3)$, with the minimum being $1 \mathrm{~mm}$ and the maximum $8 \mathrm{~mm}$. The most common contrast concentrations used were $70 / 30$ (35.9\%), $50 / 50(30.4 \%)$, and $100(28.3 \%)$.

Eighty-three TOBCs were used in the trial to administer 86 treatments at 92 treatment sites in a total of 81 subjects. The most common application for use of the TOBC was BACE (73.9\%). Other common uses included placement of a TOBC as a safety precaution $(9.1 \%)$, and balloon test occlusion (5.7\%). Uncommon or off-label uses included the treatment of vasospasm, and dilation after FD placement (Table 3). The most common balloon types/sizes 
Table 3. Reasons for TOBC use and their types

\begin{tabular}{|c|c|}
\hline \multicolumn{2}{|l|}{ Reason for TOBC use $(n=88)^{1}$} \\
\hline Balloon-assisted coiling & $73.9 \%(65 / 88)$ \\
\hline Test occlusion & $5.7 \%(5 / 88)$ \\
\hline Safety precaution & $9.1 \%(8 / 88)$ \\
\hline Other & $11.4 \%(10 / 88)$ \\
\hline Vasospasm & $60.0 \%(6 / 10)$ \\
\hline Angioplasty & $10.0 \%(1 / 10)$ \\
\hline Balloon test occlusion of left cervical ICA & $10.0 \%(1 / 10)$ \\
\hline Flow diverter (pipeline)-assisted coiling & $10.0 \%(1 / 10)$ \\
\hline Postdilatation of a flow diverter & $10.0 \%(1 / 10)$ \\
\hline \multicolumn{2}{|l|}{ Balloon type/size used } \\
\hline Compliant $/ 3.0 \times 10.0 \mathrm{~mm}$ & $6.0 \%(5 / 83)$ \\
\hline Compliant $/ 4.0 \times 10.0 \mathrm{~mm}$ & $31.3 \%(26 / 83)$ \\
\hline Compliant/4.0 × $15.0 \mathrm{~mm}$ & $7.2 \%(6 / 83)$ \\
\hline Compliant $/ 4.0 \times 20.0 \mathrm{~mm}$ & $1.2 \%(1 / 83)$ \\
\hline Compliant/5.0 × $15.0 \mathrm{~mm}$ & $2.4 \%(2 / 83)$ \\
\hline Compliant/5.0 × $20.0 \mathrm{~mm}$ & $4.8 \%(4 / 83)$ \\
\hline Super Compliant $/ 3.0 \times 5.0 \mathrm{~mm}$ & $14.5 \%(12 / 83)$ \\
\hline Super Compliant/4.0 × $10.0 \mathrm{~mm}$ & $10.8 \%(9 / 83)$ \\
\hline Super Compliant/4.0 × $7.0 \mathrm{~mm}$ & $16.9 \%(14 / 83)$ \\
\hline Super Compliant/7.0 × $7.0 \mathrm{~mm}$ & $4.8 \%(4 / 83)$ \\
\hline \multicolumn{2}{|c|}{$\begin{array}{l}\text { Total number of subjects treated: } n=81 \text {; total number of TOBCs used: } n=83 \text {; total number of TOBC appli- } \\
\text { cations/treatments: } n=86 \text {. In } 3 \text { subjects, } 1 \text { TOBC was used to administer treatment at each of } 2 \text { treatment } \\
\text { locations, and in } 1 \text { subject } 2 \text { TOBCs were used to administer treatment at } 2 \text { different treatment locations } \\
\text { (with } 1 \text { TOBC being used per location). In } 1 \text { subject, } 2 \text { TOBCs were used to administer treatment at a single } \\
\text { treatment location, as one TOBC malfunctioned and a second (replacement) TOBC had to be used to complete } \\
\text { the procedure. TOBC, TransForm }{ }^{\text {TM }} \text { Occlusion Balloon Catheter; ICA, internal carotid artery. }{ }^{1} \text { For one subject, } \\
\text { there were } 2 \text { reasons for the treatment provided (balloon-assisted coiling and as a safety precaution); } \\
\text { likewise, for another subject there were } 2 \text { reasons for the treatment provided (balloon-assisted coiling and } \\
\text { test occlusion). }\end{array}$} \\
\hline
\end{tabular}

used were the TransForm Compliant $4 \times 10 \mathrm{~mm}$ (31.4\%), the TransForm Super Compliant $4 \times 7 \mathrm{~mm}(16.9 \%)$, and the TransForm Super Compliant $3 \times 5 \mathrm{~mm}(14.5 \%)$. The most common guidewires used were the Transend ${ }^{\circledR}$ soft tip (Stryker Neurovascular) and the Synchro- $14^{\circledR}$ (Stryker Neurovascular) at 54.9 and $15.9 \%$, respectively.

The mean procedure time was $141.0( \pm 75.4) \mathrm{min}$, with a single femoral artery being the most common access site used (92.6\%). Postprocedural complete occlusion (Raymond class I) was achieved in $69.4 \%$ (50/72) of the aneurysms, while in $25 \%(18 / 72)$ of the cases, a residual neck/dog ear (Raymond class II) was left intentionally in order to keep a vessel branch open at the neck. A residual aneurysm (Raymond class III) was left in 5.6\% (4/72) of the cases. Overall TransForm balloon performance is summarized in Table 4.

\section{AEs and Complications}

Two subjects discontinued the study early. In one case, it was the decision of the physician to discontinue the study, as the investigator changed the treatment plan during the procedure. In this case, the subject was treated using commercially available flow diversion and adjunctive coiling as opposed to BACE. In the second case, the reason for early discontinuation was the death of the subject; this death was procedural in nature and was not directly related to TOBC use. Including the death, there were 2 SAEs and 3 AEs reported. All events (SAEs and AEs) were reported to be procedure related (Table 5). 
Taqi et al.: A Prospective Multicenter Trial of the TransForm Occlusion Balloon Catheter: Trial Design and Results

Table 4. TransForm ${ }^{\mathrm{TM}}$ Occlusion Balloon Catheter performance during BACE

\begin{tabular}{lll}
\hline Performance measure & $N$ & Mean value (SD) \\
\hline Visibility $^{1}$ & 83 & $1.78(0.84)$ \\
Ability to reach treatment site $^{1}$ & 83 & $1.59(0.78)$ \\
Stability during positioning $^{1}$ & 82 & $1.54(0.63)$ \\
Stability during inflation $^{1}$ & 75 & $1.56(0,68)$ \\
Stability during deflation $^{1}$ & 75 & $1.57(0.64)$ \\
Ability to stop/control blood flow $^{1}$ & 53 & $1.55(0.67)$ \\
Ability to assist in coil embolization $^{1}$ & 62 & $1.71(0.80)$ \\
Balloon inflation time, s $^{\text {Balloon deflation time, s }}$ & 83 & $4.85(3.17)$ \\
\hline
\end{tabular}

BACE, balloon-assisted coil embolization. ${ }^{1}$ Measured on a semiquantitative rating scale: $1=$ excellent, 2 = very good, 3 = good, 4 = fair, and $5=$ poor.

Table 5. Morbidity/mortality

\begin{tabular}{|c|c|c|c|c|c|c|c|c|c|}
\hline 1 & BACE & MCA & $>4$ & $\begin{array}{l}\text { Thromboembolic } \\
\text { event }\end{array}$ & $\begin{array}{l}\text { Resolved; no residual effects } \\
\text { at the end of procedure }\end{array}$ & No & No & No & No \\
\hline 3 & BACE & ICA & $<4$ & $\begin{array}{l}\text { Thrombus } \\
\text { formation }\end{array}$ & $\begin{array}{l}\text { Resolved; no residual effects } \\
\text { at the end of procedure }\end{array}$ & No & No & No & No \\
\hline 4 & BACE & ICA & $<4$ & $\begin{array}{l}\text { Thrombus } \\
\text { formation }\end{array}$ & $\begin{array}{l}\text { Resolved; no residual effects } \\
\text { at the end of procedure }\end{array}$ & No & No & No & No \\
\hline
\end{tabular}

TOBC, TransForm ${ }^{\mathrm{TM}}$ Occlusion Balloon Catheter; AE, adverse event; SAE, serious AE; ADE, adverse device effect; SADE, serious ADE; BACE, balloon-assisted coil embolization; MCA, middle cerebral artery; ICA, internal carotid artery. ${ }^{1}$ Vasospasm is an on-label indication for use in Europe but an off-label indication for use in the USA.

Table 6. Summary of BACE classified by aneurysm location and their outcome

\begin{tabular}{|c|c|c|c|c|c|c|c|c|c|c|}
\hline \multirow[t]{2}{*}{ Location } & \multirow[t]{2}{*}{$\begin{array}{l}\text { Aneurysms } \\
\text { treated at } \\
\text { this location }\end{array}$} & \multirow[t]{2}{*}{$\begin{array}{l}\text { Neck size }>4 \mathrm{~mm} \\
\text { or dome-to-neck } \\
\text { ratio }<2\end{array}$} & \multirow[t]{2}{*}{$\begin{array}{l}\text { Bifurcation } \\
\text { aneurysm }\end{array}$} & \multirow[t]{2}{*}{$\begin{array}{l}\text { Rup- } \\
\text { tured }\end{array}$} & \multicolumn{3}{|c|}{$\begin{array}{l}\text { Outcome } \\
\text { (postprocedural } \\
\text { Raymond class) }\end{array}$} & \multirow[t]{2}{*}{$\mathrm{AE}$} & \multirow[t]{2}{*}{ SAE } & \multirow[t]{2}{*}{$\mathrm{ADE}$} \\
\hline & & & & & I & II & III & & & \\
\hline MCA & 11 & 10 & 8 & 3 & 8 & 2 & 1 & 1 & 1 & Yes \\
\hline ACA & 11 & 11 & 0 & 5 & 8 & 2 & 1 & 0 & 0 & No \\
\hline Basilar & 8 & 7 & 6 & 4 & 5 & 2 & 0 & 0 & 0 & No \\
\hline ICA & 23 & 16 & 0 & 13 & 14 & 7 & 1 & 2 & 0 & No \\
\hline VA & 2 & 2 & 0 & 0 & 2 & 0 & 0 & 0 & 0 & No \\
\hline Others & 10 & 9 & 0 & 8 & 8 & 2 & 0 & 0 & 0 & No \\
\hline
\end{tabular}

BACE, balloon-assisted coil embolization; AE, adverse event; SAE, serious AE; ADE, adverse device effect; MCA, middle cerebral artery; ACA, anterior cerebral artery; ICA, internal carotid artery; VA, vertebral artery. 
Thrombus formation occurred in 4.9\% (4/81) and led to thromboembolic events in $2.5 \%$ (2/81) of the subjects. In half of these thrombotic events ( 1 thrombus formation and 1 thromboembolic event), balloon use was considered a contributing factor. In all cases, an underlying hypercoagulable state from subarachnoid hemorrhage was considered to be a contributing factor. In one case, the thromboembolic event, which was related to the guide catheter, led to a stroke (SAE) after the procedure.

Among the 83 device uses, there was one device malfunction reported (1.2\%), and a possible TOBC inflation/deflation malfunction that was identified after the database had been locked. There were no AEs reported to be associated with device malfunction. The results for the $73.9 \%$ (65/88) of the treatments in which the TOBC was used for BACE are summarized in Table 6.

\section{Discussion}

The management of both unruptured and ruptured cerebral aneurysms has changed drastically in the post-International Subarachnoid Aneurysm Trial (ISAT) era [4]. The ISAT showed improved outcomes with endovascular treatment of cerebral aneurysms as compared to craniotomy and clipping, particularly for aneurysms of the posterior circulation.

Advantages of BACE include the ability to treat wide-neck, complex, and bifurcation aneurysms with an endovascular technique. Another potential benefit includes the surgical equivalent of "proximal control" in cases of intraoperative rupture. The potential harmful effects of BACE include an increased risk of thromboembolic events, vessel rupture or dissection, and aneurysmal rupture or intraoperative perforation (IOP). Although there are some controversies in the literature, most of the case series do not support an increased risk of periprocedural complications with BACE as compared to traditional coil embolization [7, $12,25]$.

To our knowledge, no publication of a prospective multicenter registry for BACE exists in the literature. Real-world data for the TOBC were collected from a cohort of 81 subjects treated at a total of 8 study sites over the course of 13 months. The most common application for use of the TOBC was BACE (73.9\%). Other common uses included placement of a TOBC as a safety precaution (9.1\%), and balloon test occlusion (5.7\%).

The TOBC performed on the higher end of the spectrum for all attributes assessed. It was easy to navigate, was stable during inflation and deflation, was highly visible, did not lose visibility with multiple inflations/deflations, and had short inflation/deflation times (see Fig. 2, 3) The guidewire technology along the length of the balloon provides faster deflation, allowing for higher contrast levels, increased visibility, and reduced procedure times. We found no previous studies that measured in vivo inflation and deflation times of a balloon. We feel the advanced design of the TOBC resulted in these short inflation and deflation times. Since average inflation time has been shown to be a predictor of thromboembolic events [14], this may be a key performance attribute of the TOBC, but a head-to-head comparison with other balloons is needed to confirm our observation. We encourage other investigators to report this variable in studies in the future.

In this registry, thrombus formation occurred in $4.9 \%$ (4/81) and led to thromboembolic events in $2.5 \%$ (2/81) of the subjects. In half of these thrombotic events (1 thrombus formation and 1 thromboembolic event), balloon use was considered a contributing factor. In all cases, an underlying hypercoagulable state from subarachnoid hemorrhage was considered to be a contributing factor.

Thromboembolic events are considered to be the most common expected complication of BACE, although the literature is controversial. Spiotta et al. [14] have previously reported 


\section{Interventional Neurology}

\begin{tabular}{l|l}
\hline \multicolumn{2}{l}{ Intervent Neurol 2018;7:53-64 } \\
\hline DOI: 10.1159/000481518 & $\begin{array}{l}\text { O 2017 S. Karger AG, Basel } \\
\text { www.karger.com/ine }\end{array}$ \\
\hline
\end{tabular}

Taqi et al.: A Prospective Multicenter Trial of the TransForm Occlusion Balloon Catheter: Trial Design and Results
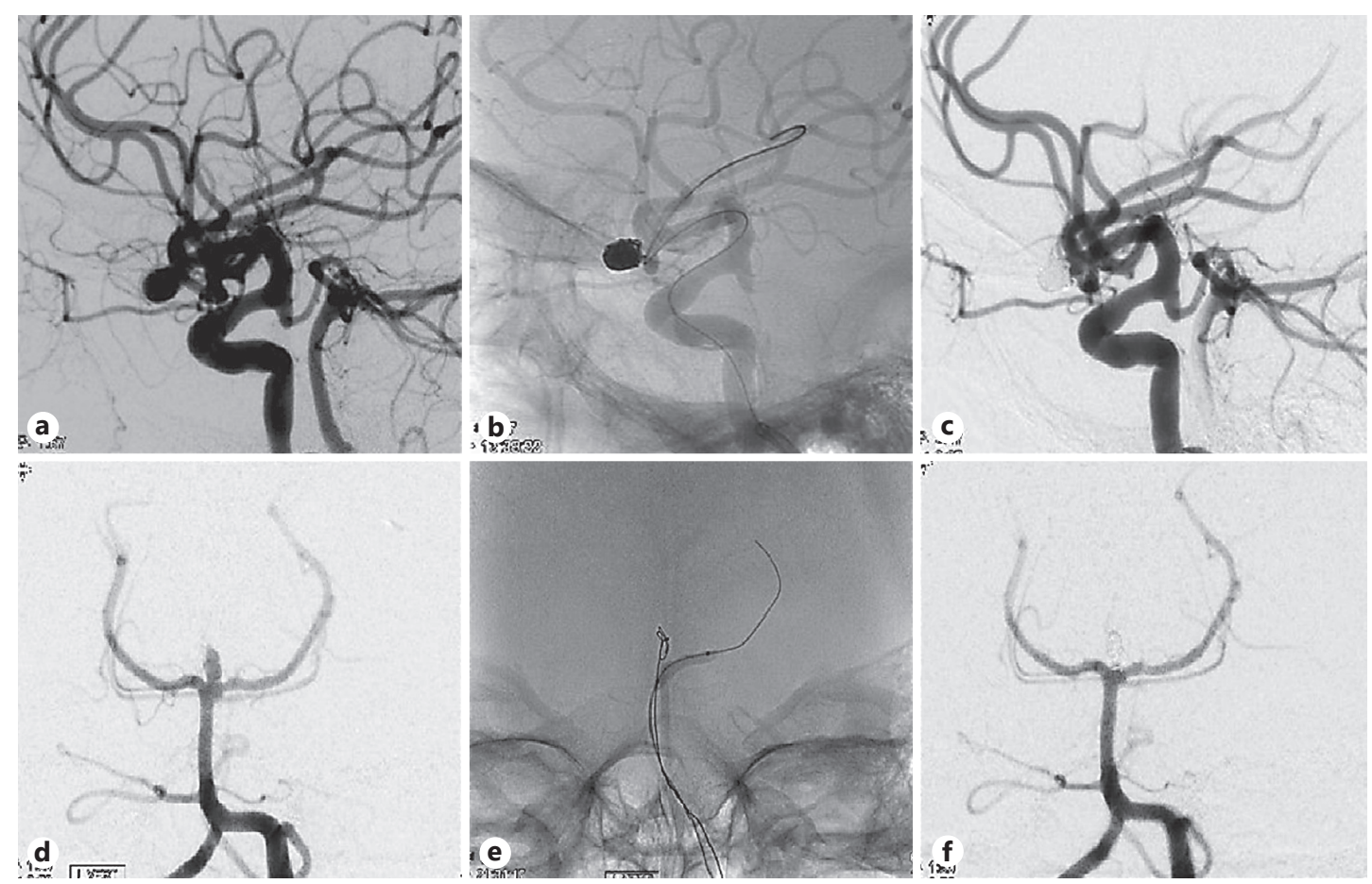

Fig. 2. a Image of left middle cerebral artery (MCA) aneurysm before embolization. b Image showing balloon inflation within the stent, demonstrating visibility and comfortability to the fusiform shape. c Image obtained after coil embolization of the left MCA, showing complete obliteration. d Image of a basilar tip aneurysm before embolization. e Image during coil embolization. $\mathbf{f}$ Image obtained after coil embolization of the basilar tip, showing complete obliteration.
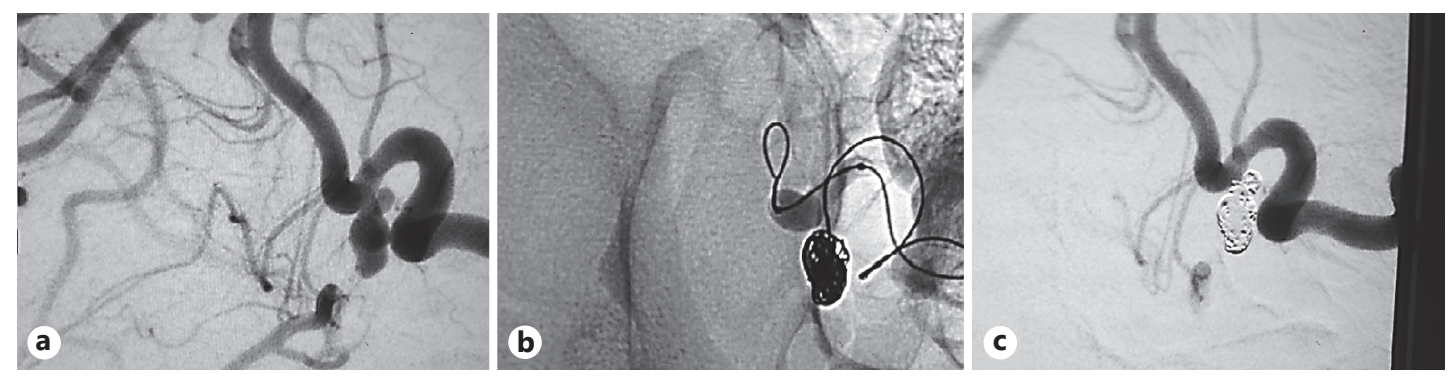

Fig. 3. a Image of a posterior communicating artery (PCOM) aneurysm before embolization. b Image during coil embolization, demonstrating the stability and visibility of the TOBC procedure. c Image obtained after coil embolization of the PCOM aneurysm, showing complete obliteration.

that total inflation time correlated with thromboembolic complications, not the number of balloon inflations or deflations. In the largest series of 864 BACE cases, Cekirge et al. [12] reported a rate of thromboembolic events of 1.7\%. Shapiro et al. [11] reported a rate of thromboembolic events of $8.1 \%$ with BACE versus $8 \%$ with traditional coil embolization. Youn et al. [2] similarly reported an $8.8 \%$ thromboembolism risk with BACE. Sluzewski et al. [25] reported a $9.8 \%$ thromboembolic risk and an overall procedural morbidity of $14.1 \%$ when performing BACE. 
In this study, none of the subjects treated suffered from a thromboembolic infarction, but no information on MRI findings were collected, and therefore the rate of asymptomatic diffusion-weighted imaging lesions in our cohort was unknown. Spiotta el al. [14] reported silent diffusion-weighted imaging lesions at $21.5 \%$ in BACE cases, and $18 \%$ in traditional coil embolization cases.

Another serious complication potentially associated with BACE is IOP of an aneurysm or vessel rupture. In this study, 1 out of 81 subjects $(1.2 \%)$ developed a vessel perforation during the procedure. In this case occurring in Europe, the subject was a 59-year-old male with a history of vasculitis, moyamoya disease, stroke/transient ischemic attack, and diabetes mellitus. A $5 \times 15 \mathrm{~mm}$ compliant TOBC was used for angioplasty of the proximal basilar artery and was inflated 5 times. The rupture occurred during the last inflation. The site PI assessed the event (vessel rupture) and determined that it was unrelated to TOBC use and was related instead to the index procedure and patient comorbidities (vessel condition due to vasculitis). There was no overinflation of the balloon, and there was no device malfunction reported for this case. This subject subsequently died and represents the only mortality in this study. Previously reported IOP rates are 5.4, 2.5, 1.6, and 0.9\% [11, 12, 14, 26].

Overall, the procedural complication rates in this study were comparable to those for coil embolization. However, since a head-to-head randomization against coil embolization was not performed, direct comparisons with coil embolization cannot be made.

Our study includes all the potential biases of a prospective registry. A screen failure log was not required, and therefore selection bias could not be ruled out. Comparisons with other balloon catheters or traditional coil embolization could not be made, as this was a single-arm registry. This registry does show that the TOBC is safe to be used in neurovascular cases for BACE or balloon occlusion. It also supports results from the literature indicating that BACE does not increase the perioperative complication risk for endovascular treatment of aneurysms and can achieve favorable results for the treatment of wide-neck and bifurcation aneurysms. Caution is advised when using the TOBC for angioplasty, as safety data are limited for such an indication.

\section{Study Limitations}

This was an observational registry to evaluate real-world data on the safety and performance of the TOBC when used during neurointerventional procedures. Since the participation of each subject enrolled in the registry was completed upon removal of the guide catheter after the procedure, there were no postprocedural radiological imaging or follow-up visits required. No core laboratory was used for the assessment of the angiographic outcomes; rather, the angiographic results were classified by Raymond class and were reported by the site PIs. Observational assessments of balloon performance were made using the semiquantitative grading scale provided. This was done by the site PIs immediately after the procedure and may have varied depending on each operator's observation. There was no independent review of the images by a core laboratory or independent adjudication of the AEs by the clinical events committee.

\section{Conclusion}

In this multicenter registry, we found use of the TOBC to be safe and effective for BACE and temporary occlusion. The TOBC performed as intended in the treatment of cerebral aneurysms in our cohort of patients. All variables assessed for TOBC performance showed very good to excellent results. No serious side effects occurred. The short inflation and deflation times and the ability to use a 0.014 -inch guidewire allowed for optimal performance of this balloon catheter. 


\begin{tabular}{l|l}
\hline DOI: $10.1159 / 000481518$ & $\begin{array}{l}\text { C 2017 S. Karger AG, Basel } \\
\text { www.karger.com/ine }\end{array}$ \\
\hline
\end{tabular}

Taqi et al.: A Prospective Multicenter Trial of the TransForm Occlusion Balloon Catheter: Trial Design and Results

\section{Disclosure Statement}

M.A.T. is a consultant for Stryker Neurovascular, and reports research grant and consulting fees from Stryker and consulting fees from Penumbra outside the submitted work. A.S.P. is a consultant for Stryker Neurovascular, and reports grants from Stryker Neurovascular, consulting fees from Stryker Neurovascular, grants from Covidien Neurovascular, consulting fees from Covidien Neurovascular, consulting fees from Codman Neurovascular, and consulting fees from the Miami Cardiovascular Institute outside the submitted work. A.T.R. is a consultant for Stryker Neurovascular, and reports consulting fees from Stryker Neurovascular outside the submitted work. O.O.Z. is a consultant for Stryker Neurovascular. C.A.G. reports having been a consultant for Stryker Neurovascular more than 36 months prior to publication and is also a consultant and physician proctor for Medtronic. J.M. is a consultant for Stryker Neurovascular.

\section{Funding Source}

This international TOBC registry was supported by Stryker Neurovascular Corporation, Fremont, CA, USA.

\section{Author Contributions}

M.A.T. was the PI for the TOBC registry; he designed the data collection tools, was responsible for performing the interventional procedures and enrolling patients in the registry at his respective center, monitored data collection for the whole trial, designed the statistical analysis, analyzed the data, and drafted and revised the paper. He is the guarantor. S.A.Q. was the primary research coordinator for the TOBC registry, was responsible for enrollment and data collection at his respective site, and participated in drafting and revising the paper. J.N.J. is an employee (biostatistician) of Stryker Neurovascular and participated in analyzing the data and preparation of the manuscript. The sponsor of the study (Stryker Neurovascular) provided assistance with statistical analysis and accumulating results while the manuscript was prepared by the PI of the study. A.S.P., B.F.F., A.T.R., C.A.G., J.M., C.J.P., and J.D.E. were registry investigators. All investigators and 0.O.Z. were responsible for performing the interventional procedures, enrolling patients in the registry, collecting data at their respective centers, critically revising the draft, and approving it before publication. All authors are accountable for the accuracy or integrity of the work at their respective centers. Dong $\mathrm{Yu}$ is an employee of Stryker Neurovascular and was the associate project manager for this registry.

\section{References}

1 Lin N, Cahill KS, Frerichs KU, Friedlander RM, Claus EB: Treatment of ruptured and unruptured cerebral aneurysms in the USA: a paradigm shift. J Neurointerv Surg 2012;4:182-189.

2 Youn SO, Lee JI, Ko JK, Lee TH, Choi CH: Endovascular treatment of wide-necked intracranial aneurysms using balloon-assisted technique with HyperForm balloon. J Korean Neurosurg Soc 2010;48:207-212.

3 Moret J, Cognard C, Weill A, Castaings L, Rey A: The "remodelling technique" in the treatment of wide neck intracranial aneurysms. Angiographic results and clinical follow-up in 56 cases. Interv Neuroradiol 1997;3: 21-35.

4 Molyneux AJ, Kerr RS, Yu LM, Clarke M, Sneade M, Yarnold JA, Sandercock P; International Subarachnoid Aneurysm Trial (ISAT) Collaborative Group: International Subarachnoid Aneurysm Trial (ISAT) of neurosurgical clipping versus endovascular coiling in 2,143 patients with ruptured intracranial aneurysms: a randomised comparison of effects on survival, dependency, seizures, rebleeding, subgroups, and aneurysm occlusion. Lancet 2005;366:809-817.

5 Aletich VA, Debrun GM, Misra M, Charbel F, Ausman JI: The remodeling technique of balloon-assisted Guglielmi detachable coil placement in wide-necked aneurysms: experience at the University of Illinois at Chicago. J Neurosurg 2000;93:388-396.

6 Nelson PK, Levy DI: Balloon-assisted coil embolization of wide-necked aneurysms of the internal carotid artery: medium-term angiographic and clinical follow-up in 22 patients. AJNR Am J Neuroradiol 2001;22: 19-26.

7 Albayram S, Selcuk H, Kara B, Bozdag E, Uzma O, Kocer N, Islak C: Thromboembolic events associated with balloon-assisted coil embolization: evaluation with diffusion-weighted MR imaging. AJNR Am J Neuroradiol 2004;25:1768-1777. 
8 Baldi S, Mounayer C, Piotin M, Spelle L, Moret J: Balloon-assisted coil placement in wide-neck bifurcation aneurysms by use of a new, compliant balloon microcatheter. AJNR Am J Neuroradiol 2003;24:1222-1225.

9 Heros RC: Complications of balloon-assisted coil embolization of intracranial aneurysms. J Neurosurg 2006; 105:393-394; discussion 394-395.

10 Ross IB, Dhillon GS: Balloon assistance as a routine adjunct to the endovascular treatment of cerebral aneurysms. Surg Neurol 2006;66:593-601; discussion 601-602.

11 Shapiro M, Babb J, Becske T, Nelson PK: Safety and efficacy of adjunctive balloon remodeling during endovascular treatment of intracranial aneurysms: a literature review. AJNR Am J Neuroradiol 2008;29:1777-1781.

12 Cekirge HS, Yavuz K, Geyik S, Saatci I: HyperForm balloon remodeling in the endovascular treatment of anterior cerebral, middle cerebral, and anterior communicating artery aneurysms: clinical and angiographic follow-up results in 800 consecutive patients. J Neurosurg 2011;114:944-953.

13 Kim JW, Park YS: Endovascular treatment of wide-necked intracranial aneurysms: techniques and outcomes in 15 patients. J Korean Neurosurg Soc 2011;49:97-101.

14 Spiotta AM, Bhalla T, Hussain MS, Sivapatham T, Batra A, Hui F, Rasmussen PA, Moskowitz SI: An analysis of inflation times during balloon-assisted aneurysm coil embolization and ischemic complications. Stroke 2011; 42:1051-1055.

15 Gory B, Kessler I, Seizem Nakiri G, Riva R, Al-Khawaldeh M, Mounayer C: Initial experience of intracranial aneurysm embolization using the balloon remodeling technique with Scepter $\mathrm{C}$, a new double-lumen balloon. Interv Neuroradiol 2012;18:284-287.

16 Rho MH, Kim BM, Suh SH, Kim DJ, Kim DI: Initial experience with the new double-lumen scepter balloon catheter for treatment of wide-necked aneurysms. Korean J Radiol 2013;14:832-840.

17 Khatri R, Cordina SM, Hassan AE, Grigoryan M, Rodriguez GJ: Sequential sidelong balloon remodeling technique in coil embolization of a wide-necked basilar tip aneurysm. J Vasc Interv Neurol 2013;6:7-9.

18 Chalouhi N, Jabbour P, Tjoumakaris S, Dumont AS, Chitale R, Rosenwasser RH, Gonzalez LF: Single-center experience with balloon-assisted coil embolization of intracranial aneurysms: safety, efficacy and indications. Clin Neurol Neurosurg 2013;115:607-613.

19 Jagadeesan BD, Siddiq F, Grande AW, Tummala RP: Modified balloon assisted coil embolization for the treatment of intracranial and cervical arterial aneurysms using coaxial dual lumen balloon microcatheters: initial experience. Neurointerv Surg 2014;6:704-707.

20 Quadri SA, Ramakrishnan V, Hariri O, Taqi MA: Early experience with the TransForm ${ }^{\mathrm{TM}}$ Occlusion Balloon Catheter: a single-center study. Interv Neurol 2014;3:174-183.

21 Bartolini B, Blanc R, Pistocchi S, Redjem H, Ciccio G, Piotin M: TransForm occlusion balloon catheter for the treatment of intracranial aneurysms, initial experience. Interv Neuroradiol 2015;21:155-160.

22 Lazzaro MA, Darkhabani Z, Zaidat 00, Fitzsimmons BF: Initial experience with the coaxial dual-lumen ascent balloon catheter for wide-neck aneurysm coil embolization. Front Neurol 2011;2:52.

23 Raymond J, Roy D: Safety and efficacy of endovascular treatment of acutely ruptured aneurysms. Neurosurgery 1997;41:1235-1245; discussion 1245-1246.

24 Raymond J, Guilbert F, Weill A, Georganos SA, Juravsky L, Lambert A, Lamoureux J, Chagnon M, Roy D: Longterm angiographic recurrences after selective endovascular treatment of aneurysms with detachable coils. Stroke 2003;34:1398-1403.

25 Sluzewski M, van Rooij WJ, Cloft H: Is the risk of balloon assistance underinflated? AJNR Am J Neuroradiol 2008;29:1782.

26 Elijovich L, Higashida RT, Lawton MT, Duckwiler G, Giannotta S, Johnston SC; Cerebral Aneurysm Rerupture after Treatment (CARAT) Investigators: Predictors and outcomes of intraprocedural rupture in patients treated for ruptured intracranial aneurysms: the CARAT study. Stroke 2008;39:1501-1506. 